\title{
Somatosensory evoked potentials after multisegmental upper limb stimulation in diagnosis of cervical spondylotic myelopathy
}

\author{
Domenico Restuccia, Massimiliano Valeriani, Vincenzo Di Lazzaro, Pietro Tonali, \\ François Mauguière
}

\begin{abstract}
Radial, median, and ulnar nerve somatosensory evoked potentials (SEPs) were recorded, with non-cephalic reference montage, in 38 patients with clinical signs of cervical myelopathy and MRI evidence of spondylotic compression of the cervical cord. Upper limb SEPs are useful in spondylotic myelopathy because SEPs were abnormal in all patients for at least one of the stimulated nerves and SEP abnormalities were bilateral in all patients but one. Reduction of the amplitude of the N13 potential indicating a segmental dysfunction of the cervical cord was the most frequent abnormality; it occurred in $93.4 \%, 84.2 \%$, and $64.5 \%$ of radial, median, and ulnar nerve SEPs respectively. A second finding was that the P14 far-field potential was more sensitive than the cortical $\mathrm{N} 20$ potential to slowing of conduction in the dorsal column fibres. The high percentage of N13 abnormalities in the radial and median rather than in the ulnar nerve SEPs correlated well with the radiological compression level, mainly involving the C5-C6 vertebral segments. Therefore the recording of the $\mathrm{N13}$ response is a reliable diagnostic tool in patients with cervical spondylotic myelopathy and P14 abnormalities, though less frequent, can be useful in assessing subclinical dorsal column dysfunction.
\end{abstract}

$(\mathcal{F}$ Neurol Neurosurg Psychiatry 1994;57:301-308)

Spondylotic changes of the cervical spine are the most common cause of cervical myelopathy or radiculopathy. ${ }^{1}$ The diagnosis of cervical spondylotic myelopathy is based on the combination of signs suggesting involvement of long pathways (spastic paraparesis associated with a variable degree of lower limb ataxia), and dysfunction of motor and sensory neurones in the cervical grey matter. ${ }^{2}$ Nevertheless, sensory motor and reflex changes in the upper limbs can be missing ${ }^{3}$ and, in the absence of sensory deficits, cervical spondylotic myelopathy can be confused with other degenerative diseases such as amyotrophic lateral sclerosis.

Magnetic resonance imaging (MRI) of the cord can show several types of signal abnormalities at the level of cord compression, ${ }^{45}$ but gives no information on cervical cord dysfunction in cervical spondylotic myelopathy.
Therefore, it is clinically relevant to develop complementary investigations for assessing cord dysfunction at the cervical level.

Somatosensory evoked potentials (SEPs) have been used to disclose abnormalities of ascending sensory pathways in cervical spondylotic myelopathy. Previous studies with cephalic reference montages showed that dorsal column dysfunction can be demonstrated in $43 \%$ to $100 \%$ of patients by lower limb SEPs, in $57 \%$ to $74 \%$ of patients by ulnar nerve SEPs, and in $24 \%$ to $59 \%$ of patients by median nerve SEPs. ${ }^{6-10}$ Abnormal lower limb SEPs are, however, of no value for localising the dysfunction at the cervical level; moreover, in previous studies upper limb SEPs rarely showed abnormalities in patients without sensory deficits.

Non-cephalic reference recordings of SEPs allow a separate analysis of the dorsal horn N13 response and of the P14 potential, the latency of which reflects the transit time of the ascending volley up to the lower brainstem level. Abnormalities of the N13 potential have been found in diseases affecting the central grey matter ${ }^{11-15}$ and in a selected population of patients with cervical spondylotic myelopathy but with normal sensation. ${ }^{16}$ Moreover, prolonged P14 latencies in relation to a conduction slowing in dorsal columns were found in focal cervical cord lesions as well as in multiple sclerosis. ${ }^{17-20}$ Our study considers the question whether the diagnostic yield of SEPs in cervical spondylotic myelopathy can be improved by assessing separately dorsal column and dorsal horn responses to stimulation of median, radial, and ulnar nerves in a large population of patients with cervical spondylotic myelopathy.

\section{Patients and methods}

PATIENTS

We studied 38 patients (mean age 56 (range 37-77) years; 29 men) with cervical spondylosis confirmed by MRI. All patients showed spastic weakness of the lower limbs, brisk lower limb tendon jerks, and a unilateral or bilateral Babinski sign. Mild weakness and wasting in upper limbs or reduction or absence of at least one of the upper limb tendon reflexes was found in 22 patients. No patient complained of pain or paraesthesia in the upper limbs. Joint and touch sensation in the upper limbs was impaired in 17 patients; there was segmental pain and temperature sensation impairment in the upper limbs of 
Table 1 Normative data

\begin{tabular}{|c|c|c|c|}
\hline & $\operatorname{Mean}(S D)$ & Range & $\begin{array}{l}\text { Limit of normal values } \\
(\text { mean }(3 S D))\end{array}$ \\
\hline $\begin{array}{l}\text { Radial nerve SEPs (16 control subjects): } \\
\begin{array}{ll}\text { Interpeak intervals (ms) } & \text { P9-N13 } \\
& \text { P9-P14 } \\
& \text { P14-N20 } \\
& \text { P9-N20 } \\
\text { N13/P9 amplitude ratio (logarithmic values) }\end{array}\end{array}$ & $\begin{array}{c}4 \cdot 4(0 \cdot 3) \\
5 \cdot 4(0 \cdot 3) \\
4 \cdot 7(0 \cdot 5) \\
10 \cdot 1(0 \cdot 5) \\
0 \cdot 291(0 \cdot 125)\end{array}$ & $\begin{array}{l}3 \cdot 8-5 \\
4 \cdot 7-5 \cdot 8 \\
3 \cdot 8-5 \cdot 7 \\
9-10 \cdot 9 \\
0 \cdot 079-0 \cdot 602\end{array}$ & $\begin{array}{c}5 \cdot 3 \\
6 \cdot 3 \\
6 \cdot 2 \\
11 \cdot 6 \\
-0.084 \\
0 \cdot 82^{\star}\end{array}$ \\
\hline $\begin{array}{lc}\text { Median nerve SEPs (20 control subjects): } \\
\begin{array}{lc}\text { Interpeak intervals (ms) } & \text { P9-N13 } \\
& \text { P9-P14 } \\
& \text { P14-N20 } \\
& \text { P9-N20 } \\
\text { N13/P9 amplitude ratio (logarithmic values) }\end{array}\end{array}$ & $\begin{array}{c}4 \cdot 3(0.4) \\
5 \cdot 4(0.5) \\
4.9(0.5) \\
10 \cdot 3(0.5) \\
0 \cdot 274(0.09)\end{array}$ & $\begin{array}{l}3 \cdot 6-5 \cdot 4 \\
4 \cdot 2-6 \cdot 6 \\
3 \cdot 8-5 \cdot 9 \\
9 \cdot 2-11 \cdot 2 \\
0 \cdot 125-0 \cdot 505\end{array}$ & $\begin{array}{l}5 \cdot 5 \\
6 \cdot 9 \\
6 \cdot 4 \\
11 \cdot 8 \\
0 \cdot 004 \\
1^{\star}\end{array}$ \\
\hline $\begin{array}{lc}\text { Ulnar nerve SEPs (16 control subjects): } \\
\text { Interpeak intervals (ms) } & \text { P9-N13 } \\
& \text { P9-P14 } \\
& \text { P14-N20 } \\
& \text { P9-N20 } \\
\text { N13/P9 amplitude ratio (logarithmic values) }\end{array}$ & $\begin{array}{l}4 \cdot 4(0 \cdot 4) \\
5 \cdot 7(0 \cdot 5) \\
4 \cdot 7(0 \cdot 5) \\
10 \cdot 4(0 \cdot 5) \\
0 \cdot 252(0 \cdot 116)\end{array}$ & $\begin{array}{l}3 \cdot 8-5 \cdot 2 \\
4 \cdot 9-6 \cdot 7 \\
3 \cdot 6-5 \cdot 4 \\
9 \cdot 4-11 \cdot 3 \\
0 \cdot 102-0 \cdot 602\end{array}$ & $\begin{array}{c}5 \cdot 6 \\
7 \cdot 2 \\
6 \cdot 2 \\
11 \cdot 9 \\
-0 \cdot 009 \\
0 \cdot 81^{\star}\end{array}$ \\
\hline
\end{tabular}

${ }^{\star}$ Corresponding absolute value.

13 patients. In nine patients there was an increased signal on T2-weighted MRI scans of the cord at the cervical level; in one patient MRI showed a segmental atrophy of the cervical cord.

Brain MRI, and CSF and blood tests were also performed to exclude other pathological conditions such as multiple sclerosis or vitamin B-12 deficiency. All patients had nerve conduction and concentric needle EMG examinations. Motor and sensory nerve conduction velocity studies were performed in the upper limbs with standard techniques. ${ }^{21}$ EMG activity in upper limb muscles was considered abnormal when there were fibrillations and positive sharp waves in two or more areas of the muscle under study. Upper limb nerve conduction velocities were within normal limits in all patients. Concentric needle examination showed abnormalities confined to upper limb muscles in 22 patients.

\section{SEP RECORDING PROCEDURE}

For SEP recording, patients lay on a couch in a warm and semidarkened room. Stimuli $(0 \cdot 3$ ms square pulses) were delivered at the rate of $5 \mathrm{~Hz}$ with skin electrodes (cathode proximal) at motor threshold intensity for median and ulnar nerve SEPs and at three times the sensory threshold intensity for radial nerve SEPs. Stimulations were delivered at the wrist for median and radial nerves and above the ulnar groove at the elbow for the ulnar nerve. The filter bandpass was $10-3000 \mathrm{~Hz}$ ( $-3 \mathrm{~dB}$ at cut off point, $6 \mathrm{~dB}$ per octave); the analysis time was $50 \mathrm{~ms}$ with a bin width of $98 \mu \mathrm{s}$. Samples with excess interference were automatically edited out of the average. Two averages of 2048 or 4096 trials each were obtained and drawn out by the computer on an $\mathrm{X}-\mathrm{Y}$ plotter. The recording electrodes (impedance below $5 \mathrm{kohm}$ ) were placed in the supraclavicular fossa (Erb's point), over the spinous process of the 6th cervical vertebra (Cv6) and in the parietal scalp regions contralateral and ipsilateral to stimulation. The Erb's point electrode was referred to $\mathrm{Fz}$ and the parietal scalp electrodes to the shoulder contralateral to the stimulated side. For the recording of the cervical N13 potential we connected grid 1 of the amplifier to the Cv6 electrode and grid 2 to an electrode located immediately above the thyroid cartilage. This electrode site is referred to in the text and figures as anterior cervical (AC). The rationale for this Cv6 to AC montage has been discussed in detail in previous studies ${ }^{1322}$; firstly it records the activity generated by the transverse dipolar source of the N13 potential with a maximal amplitude. Secondly it permits the selective assessment of the amplitude of the dorsal horn response as it does not record potentials generated above the foramen magnum and tends to cancel the N11 potential, which reflects the ascending volley in the dorsal columns ${ }^{23-26}$ and is picked up by both Cv6 and AC electrodes. ${ }^{22}{ }^{24}$ A stationary P9 potential, reflecting the positive front of the afferent volley in cervical roots, ${ }^{27}$ is also picked up by both Cv6 and AC electrodes and the waveform resulting from the algebraic subtraction of the larger AC P9 from the smaller Cv6 P9 is made of a small negativepositive diphasic deflection preceding the cervical N13. ${ }^{1322}$

NORMATIVE DATA

To match our control subjects for age with patients with cervical spondylotic myelopathy we selected from the laboratory normative data $^{16}$ those collected in normal subjects over 40 years of age (20 subjects (age range $40-82$, mean 52.7, seven men) for median nerve SEPs, 16 subjects (age range 40-82, mean 53.2 , seven men) for radial and ulnar nerve SEPs), see table 1. For assessing the conduction time in somatosensory pathways we measured the peaking latencies of Erb's point N9, cervical N13, scalp far-field P9 and P14, and contralateral parietal $\mathrm{N} 20$ potentials. To eliminate interindividual variations related to arm length, P9-N13, P9-P14, P14-N20, and P9-N20 interpeak intervals were also calculated.

The amplitude of the N13 potential was assessed by calculating the N13/P9 amplitude ratio using the $\mathrm{Cv} 6-\mathrm{AC}$ traces $^{13-16}$ as shown in fig 1 . 
Figure 1 SEPs evoked by stimulation of $(A)$ right radial, (B) median, and (C) ulnar nerves in a 46-year-old control subject. Two traces obtained on two successive runs of 2024 (for the median

and ulnar nerves) or 4096 (for the radial nerve) are superimposed. Erb-Fz = Erb's point referred to a forehead electrode $\left(F_{z}\right)$; the P14 potential picked up from the frontal electrode is injected as an "N14" negativity; Cv6$A C=$ spinous process of the sixth cervical vertebra, referred to an anterior cervical electrode (AC); $\mathrm{Par}_{c}-\mathrm{Sh}=$ parietal electrode contralateral to the stimulus, referred to the shoulder contralateral to the stimulus (noncephalic reference electrode); Par $_{c}$ Par $_{i}=$ parietal electrode contralateral to the stimulus, referred to the parietal electrode ipsilateral to the stimulus; using this derivation the subcortical far-field potentials preceding the $N 20$ response are cancelled out. (D) Method used for measuring the amplitude of P9 (1) and N13 (2) as well as the N13/P9 amplitude ratio in the Cv6-AC trace.
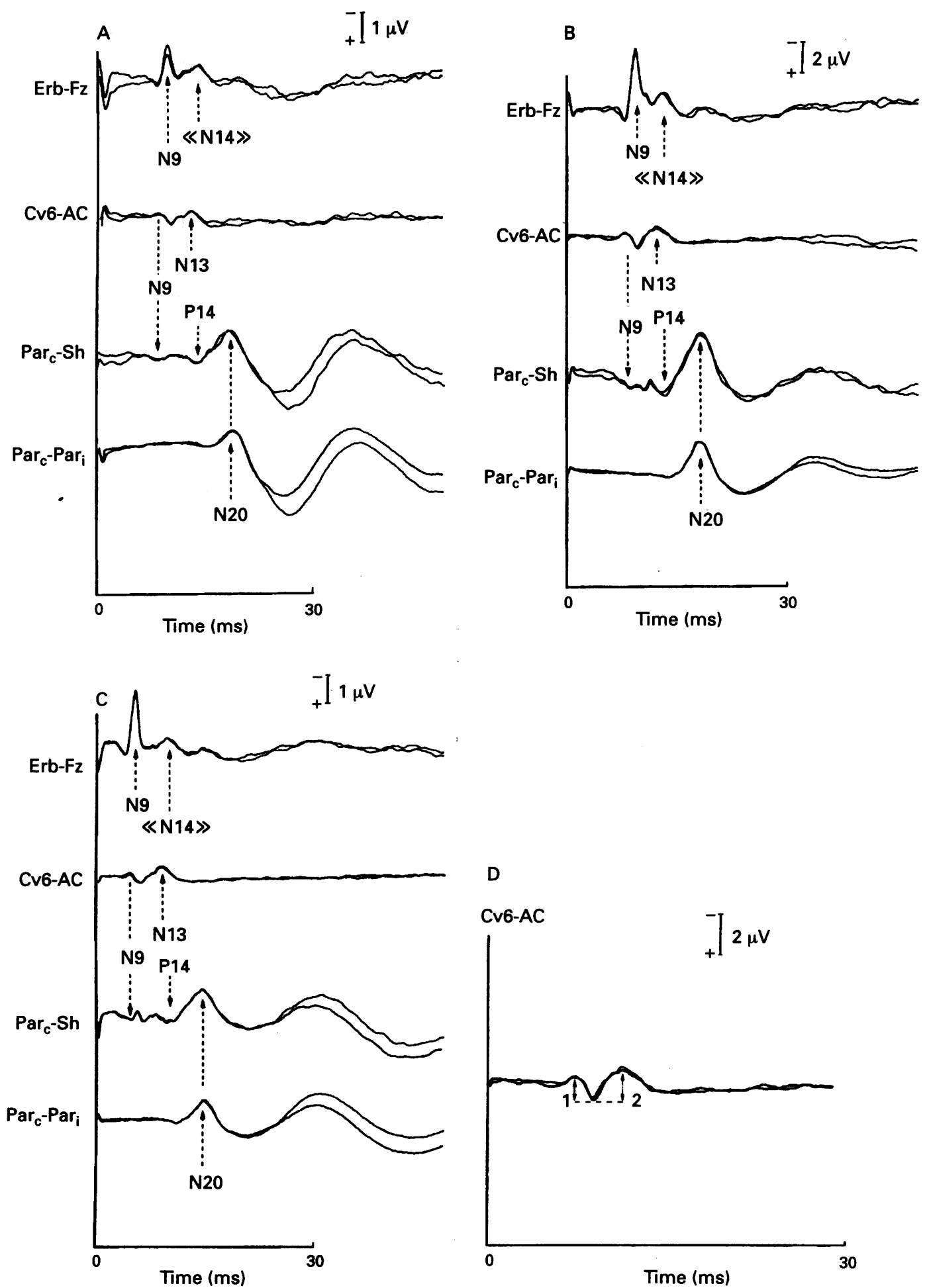

Results

All patients but one showed abnormal SEPs on both sides, at least for one of the stimulated nerves. In only one patient SEP abnormalities were limited to the right side. The latency of the N9 and P9 responses were always within normal limits, as well as the P9-N13 interpeak interval and the N13 latency, when the N13 response was identifiable. Abnormalities in $\mathrm{N} 20$ potential were always associated with an abnormal P14 potential.

N13 ABNORMALITIES

Reduced or absent N13 potential was found 
Table 2 Correlation between clinical signs and distribution of SEP abnormalities

\begin{tabular}{|c|c|c|c|c|}
\hline \multirow[b]{2}{*}{ Clinical signs } & \multicolumn{3}{|l|}{ Abnormal } & \multirow{2}{*}{$\frac{\text { Normal }}{\text { In all three nerves }}$} \\
\hline & Radial, median, ulnar & Radial, median & Radial & \\
\hline $\begin{array}{l}\text { Lower motor neuron signs } \\
\text { Pain and temperature } \\
\text { segmental hypesthesia }\end{array}$ & $\begin{array}{l}31 / 49 \text { upper limbs } \\
16 / 49 \text { upper limbs }\end{array}$ & $\begin{array}{l}\text { N13 response } \\
8 / 15 \text { upper limbs } \\
4 / 15 \text { upper limbs }\end{array}$ & $\begin{array}{l}\text { 3/7 upper limbs } \\
\text { 3/7 upper limbs }\end{array}$ & $\begin{array}{l}\text { 0/5 upper limbs } \\
\text { 0/5 upper limbs }\end{array}$ \\
\hline Joint and touch hypesthesia & 22/49 upper limbs & 4/15 upper limbs & 1/7 upper limbs & $4 / 5$ upper limbs \\
\hline $\begin{array}{l}\text { Lower motor neuron signs } \\
\text { Pain and temperature } \\
\text { segmental hypesthesia }\end{array}$ & $\begin{array}{r}\text { 19/30 upper limbs } \\
8 / 30 \text { upper limbs }\end{array}$ & $\begin{array}{l}\text { P } 14 \text { response } \\
\text { 3/6 upper limbs } \\
6 / 6 \text { upper limbs }\end{array}$ & $\begin{array}{l}\text { 5/11 upper limbs } \\
\text { 4/11 upper limbs }\end{array}$ & $\begin{array}{r}\text { 15/29 upper limbs } \\
5 / 29 \text { upper limbs }\end{array}$ \\
\hline Joint and touch hypesthesia & $23 / 30$ upper limbs & 1/6 upper limbs & $7 / 11$ upper limbs & 0/29 upper limbs \\
\hline $\begin{array}{l}\text { Lower motor neuron signs } \\
\text { Pain and temperature } \\
\text { segmental hypesthesia }\end{array}$ & $\begin{array}{l}\text { 18/29 upper limbs } \\
7 / 29 \text { upper limbs }\end{array}$ & $\begin{array}{l}N 20 \text { response } \\
3 / 4 \text { upper limbs } \\
4 / 4 \text { upper limbs }\end{array}$ & $\begin{array}{l}\text { 3/8 upper limbs } \\
\text { 4/8 upper limbs }\end{array}$ & $\begin{array}{l}\text { 18/35 upper limbs } \\
7 / 35 \text { upper limbs }\end{array}$ \\
\hline Joint and touch hypesthesia & 22/29 upper limbs & 1/4 upper limbs & 6/8 upper limbs & 2/35 upper limbs \\
\hline
\end{tabular}

were bilateral in four patients and unilateral in seven. When $\mathrm{N} 13$ was abnormal for only one nerve, only radial nerve SEPs were affected. This was the situation in seven upper limbs $(9 \cdot 2 \%)$. These abnormalities were bilateral in two patients and unilateral in three.

A normal N13 was found whatever the stimulated nerve in five upper limbs; these normal spinal responses were bilateral in two patients and found after stimulation of the left side in one patient. Table 2 shows correlations between $\mathrm{N} 13$ findings and clinical signs in the corresponding upper limb.

\section{P14 ABNORMALITIES}

The P14 potential was absent or delayed after stimulation of at least one nerve in 24 patients $(63 \cdot 1 \%)$. Abnormal P14 was found in 30,36 , and 47 of the 76 radial, median,

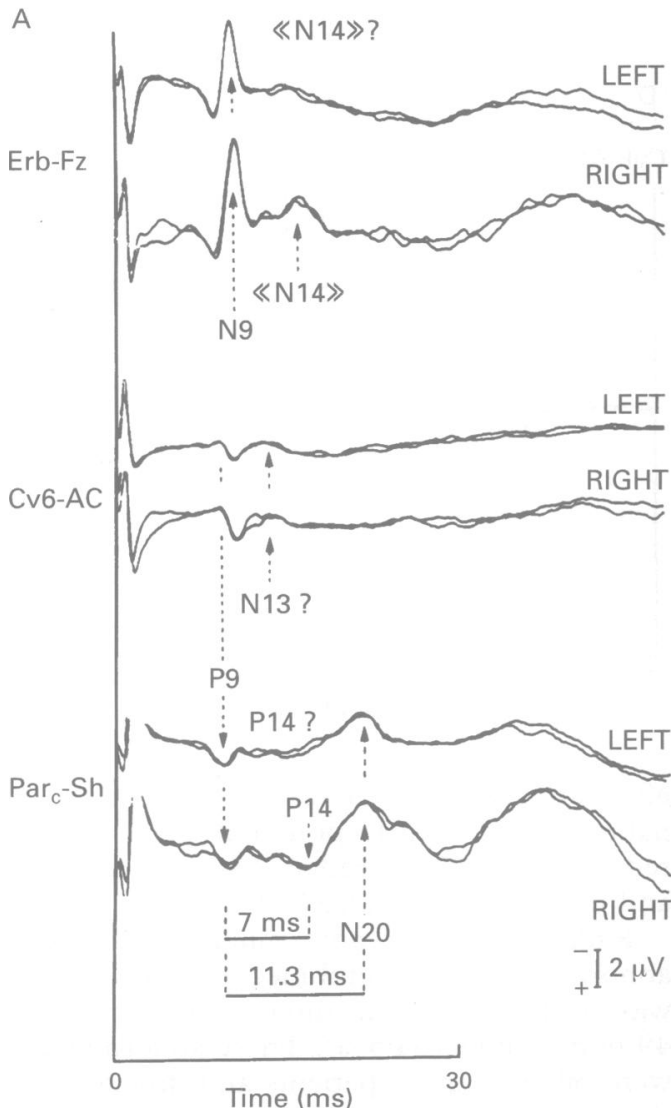

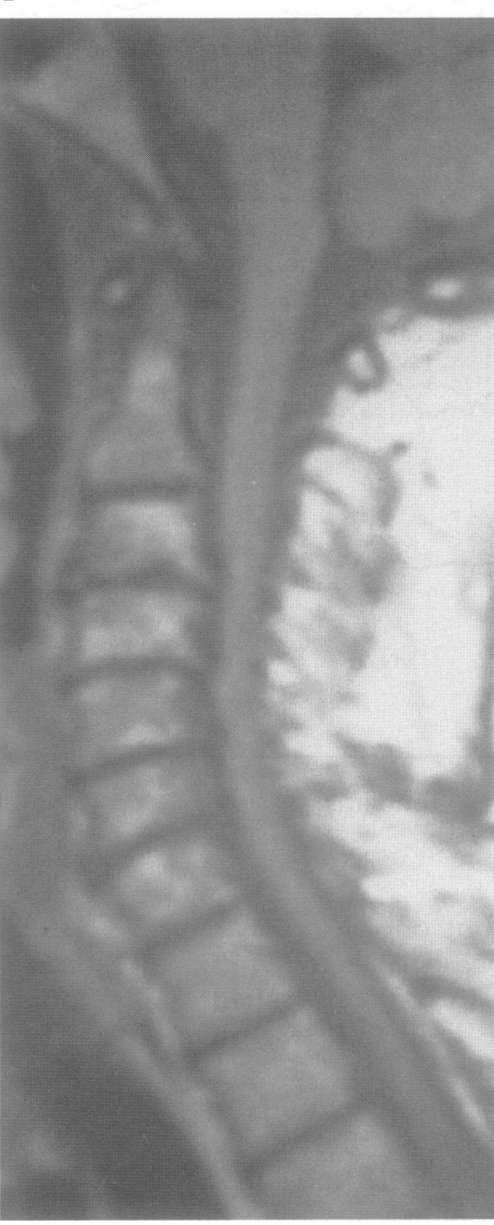

C

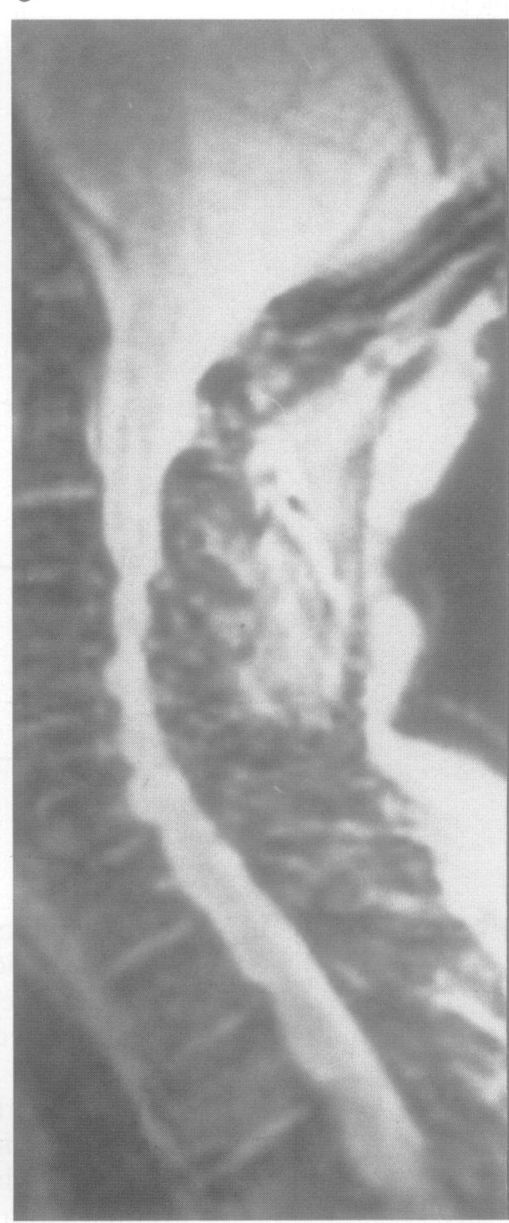

Figure 2 (A) Delayed or absent P14 with normal latency N20 after stimulation of the median nerve. Right and left median nerve SEPs are illustrated with the same abbreviations as in fig 1 . The peak latencies of N9 and P9 responses were within normal limits. The N13 potential was absent after stimulation of the right median, and reduced after stimulation of the left median nerve. Whereas the N20 latencies, as well as the P9-N20 intervals, were still within normal limits, the P9-P14 interval was slightly increased after stimulation of the right median nerve and the P14 was unrecognisable after stimulation of the lefi median nerve. $(B, C)$ The cervical spinal cord MRI (T1-and T2-weighted) showed a stenosis of the cervical cord with spondylotic cord compression at the C3-C4,C4-C5, and C5-C6 levels. 
A

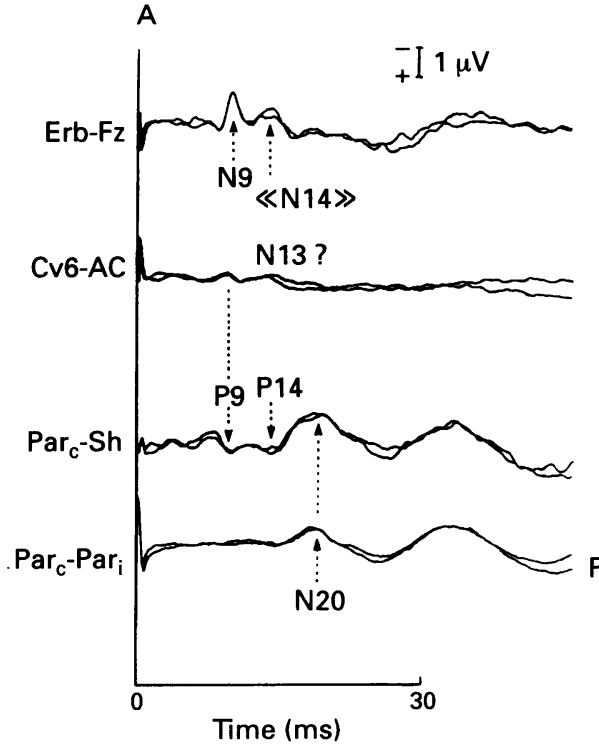

B

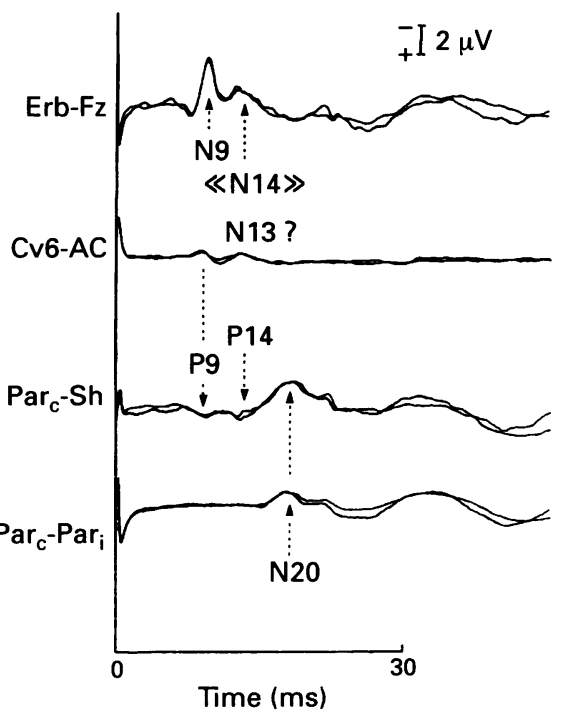

C

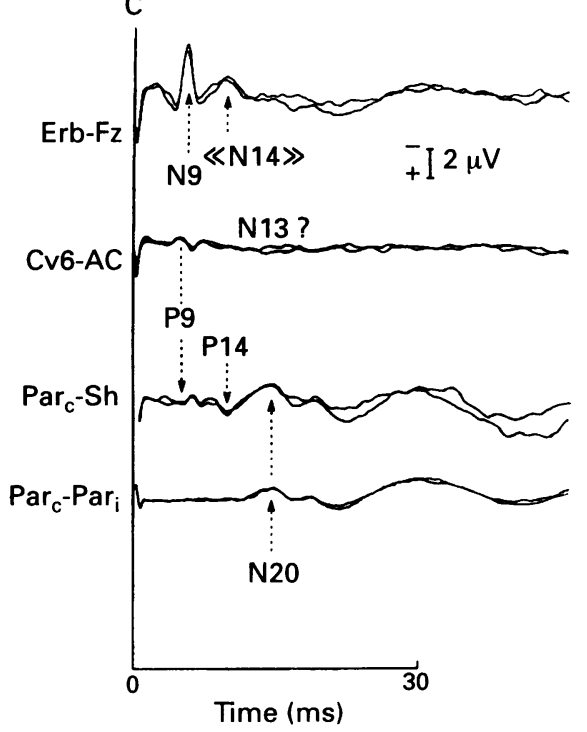

Figure 3 Association of normal scalp SEPs and abnormal spinal SEPs after stimulation of all three nerves. (A) Right radial, (B) median, and (C) ulnar nerve SEPs. Same presentation as in figs 1 and 2. The peaking latencies of N9, P9, P14, and N20 responses, as well as P9-P14 and P14-N20 interpeak intervals were within normal limits. N13 potential was absent or reduced after stimulation of all three nerves.

D

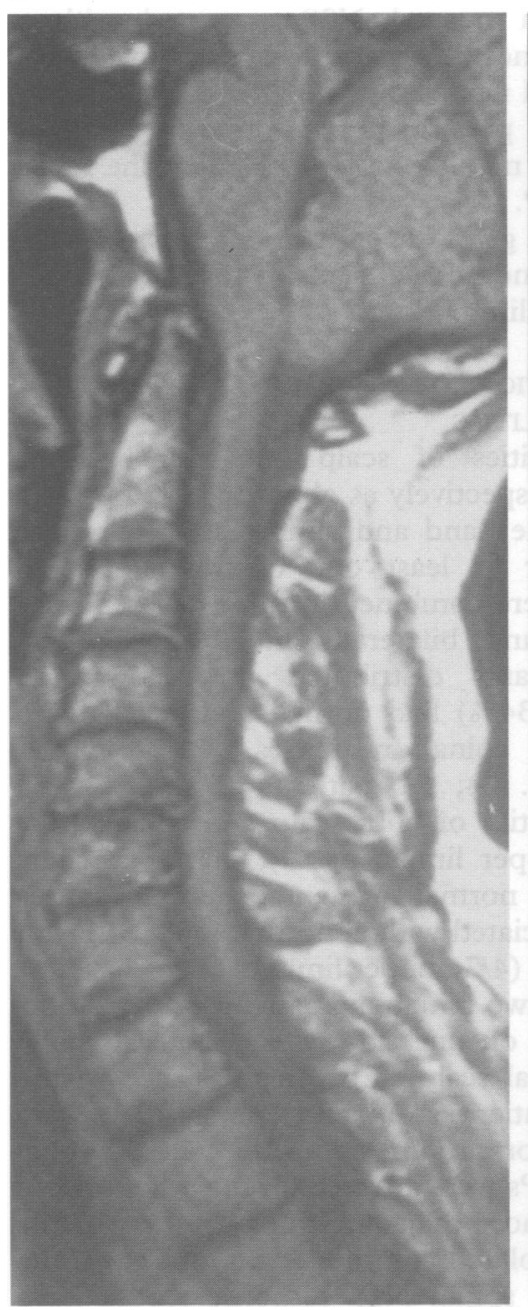

Figure 3 contd (D, E) Cervical spinal cord MRI (T1-and T2-weighted) showed a compression at C5-C6 level.

and ulnar nerve SEPs respectively; P14 was abnormal for the three tested nerves in 30 upper limbs $(39 \cdot 5 \%)$. These abnormalities were bilateral in 13 patients and unilateral in four. In all cases where the P14 was abnormal for only two of the three tested nerves the pattern consisted of abnormal P14 in median and ulnar nerve SEPs with normal radial nerve scalp SEPs. This was found in six upper limbs $(7 \cdot 9 \%)$. This type of SEP abnormality was bilateral in one patient and unilateral in four. When P14 was abnormal for only one nerve, only ulnar nerve SEPs were affected. This was found in 11 upper limbs $(14.5 \%)$, bilaterally in five patients, and unilaterally in one.

Normal radial, median, and ulnar nerve P14 potentials were found in 29 upper limbs $(38 \cdot 1 \%)$. This finding was bilateral in 14 patients and unilateral in one. Table 2 gives the correlations between P14 findings and clinical signs in the corresponding upper limb.

\section{N20 ABNORMALITIES}

N20 potential was absent or delayed after stimulation of at least one nerve in 22 patients $(57 \cdot 9 \%)$. The $\mathrm{N} 20$ potential was abnormal in 29/76 of radial, 33/76 of median, and $41 / 76$ of ulnar nerve SEPs. Radial, median, and ulnar scalp N20 abnormalities were combined as follows. N20 was abnormal for the three tested nerves in 29 upper limbs (38.1\%). These abnormalities were bilateral in 13 patients and unilateral in three. When N20 was abnormal for only two of the three tested nerves the pattern consisted in all cases of abnormal N20 in median and ulnar nerve SEPs with normal radial nerve N20. This was found in four upper limbs (5.3\%), bilaterally in one patient, and unilaterally in two. When N20 was abnormal for only one nerve, only ulnar nerve SEPs were affected. This was the situation in eight upper limbs $(10.5 \%)$. These abnormalities were bilateral in three patients and unilateral in two.

The N20 potential was normal for all tested nerves in 35 upper limbs (46\%). This finding was bilateral in 16 patients and uni- 

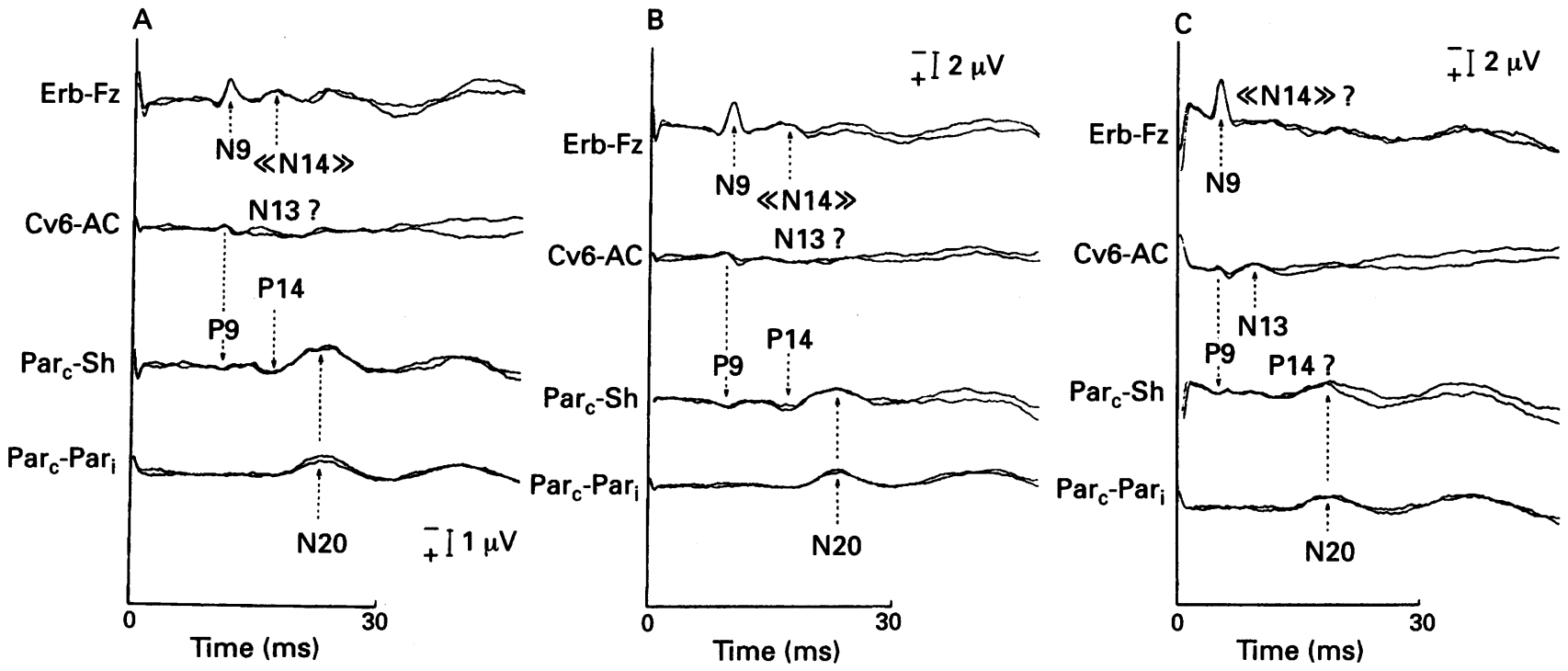

Figure 4 Association of abnormal scalp and spinal SEPs. (A) Right radial, (B) median and (C) ulnar nerve SEPs. Same presentation as in figs 1-3. The peak latencies of $N 9$ and $P 9$ responses were within normal limits. The N13 potential was absent after stimulation of the radial and median nerves, but still normal after stimulation of the ulnar nerve. The peak latencies of the P14 response, as well as the P9-P14 intervals, were delayed after stimulation of the radial and median nerves and not evaluable after stimulation of the ulnar nerve.

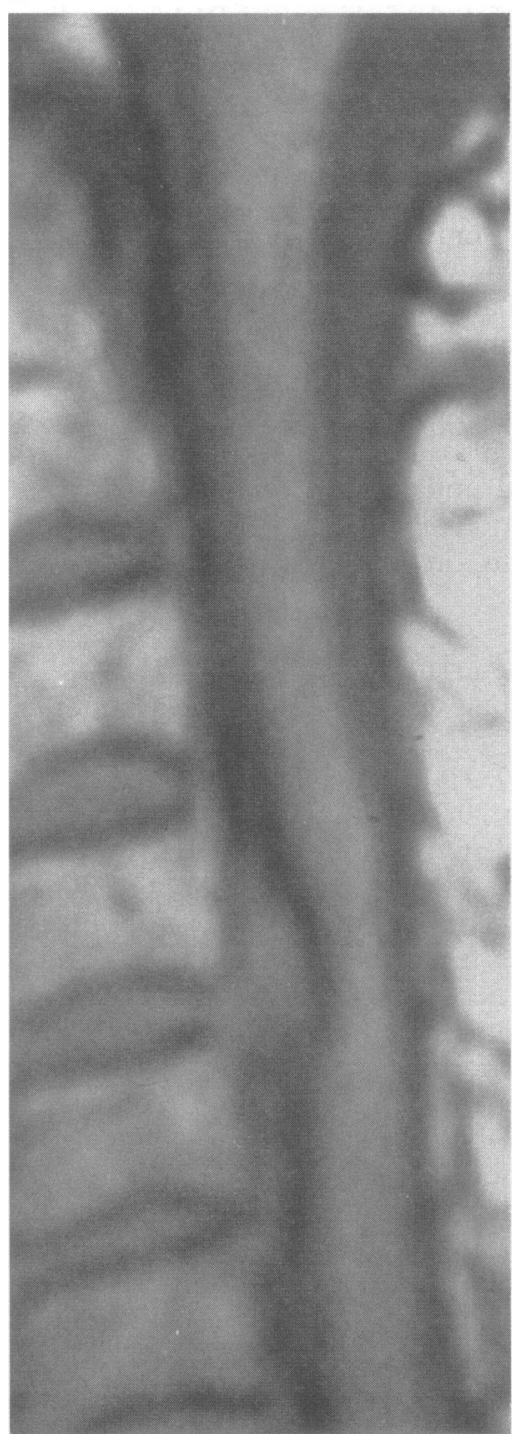

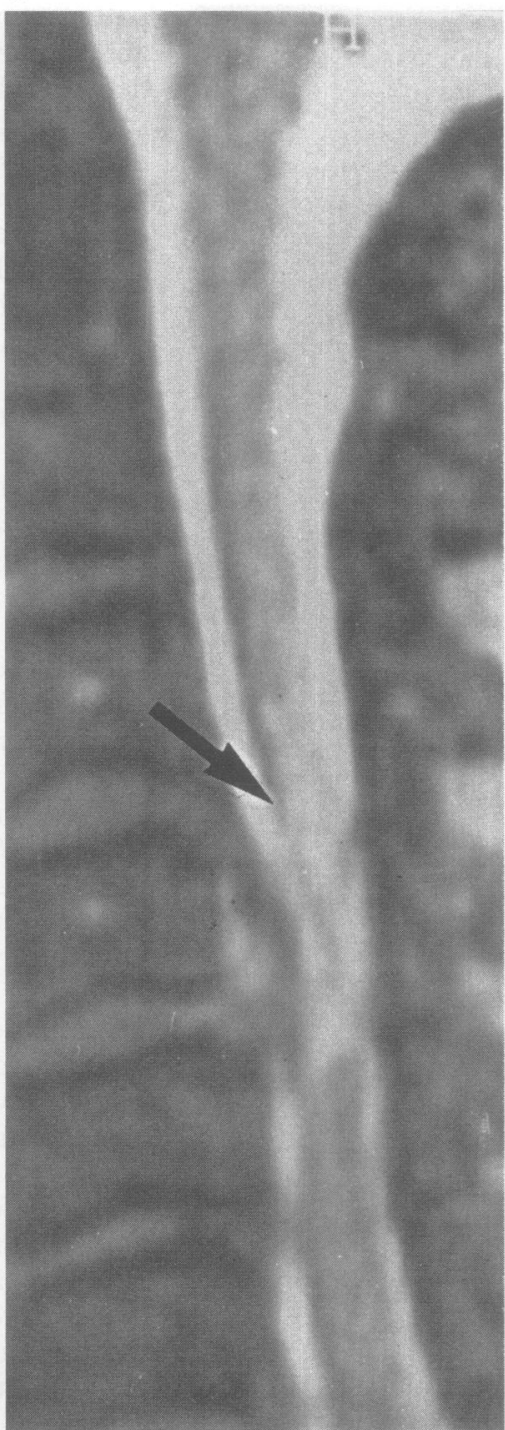

Figure 4 contd (D) Cervical spinal cord MRI (T1-weighted) showed a stenosis of the cervical canal with compression at C4-C5. (E) T2-weighted scan showed an intramedullary hyperintensity (arrow). lateral in three.

Thus a normal N20 coexisted with a clearly abnormal P14 for at least one of the stimulated nerves in five patients. Fig 2 illustrates this pattern; it was found in six ulnar and three median nerve SEPs and one radial nerve SEP.

Table 2 gives the correlations between N20 findings and clinical signs in the corresponding upper limb.

\section{COMBINATIONS OF SCALP AND SPINAL SEP ABNORMALITIES}

Abnormalities of scalp and spinal SEPs, defined respectively as abnormal $\mathrm{N} 20$ or P14 on the one hand and abnormal $\mathrm{N} 13$ on the other, for at least one of the stimulated nerves, were combined in three different patterns, found bilaterally in 36 of our 38 patients and distributed as follows: 13 patients (34\%) had normal scalp SEPs with abnormal spinal responses (26/76 upper limbs; fig. 3); 21 patients (55\%) showed abnormalities of both scalp and spinal SEPs (42/76 upper limbs; fig. 4); in two patients only $(5 \%)$ normal segmental spinal responses were associated with abnormal scalp SEPs on both sides (4/76 upper limbs).

Of the two remaining patients one had normal SEPs on one side with abnormal spinal and normal scalp SEPs on the other; in the second patient scalp and spinal SEPs were both abnormal on one side whereas only spinal SEPs were affected on the other side.

Thus more than one third of our patients with an isolated amplitude abnormality of the segmental spinal N13 response would have been considered as having normal upper limb SEPs if recorded with a conventional frontal reference montage, which does not allow a selective assessment of this variable. ${ }^{14}$

CLINICAL CORRELATIONS (TABLE 3)

Abnormal P14 and N20 were significantly 
correlated with loss or reduced joint and touch sensation $\left(\chi^{2}, \mathrm{p}<0.05\right)$, but neither with segmental pain and temperature hyperaesthesia, nor with absent or reduced tendon reflexes in the corresponding upper limb.

Abnormal N13 was correlated with absent or reduced tendon reflexes in the corresponding upper limb $\left(\chi^{2}, \mathrm{p}<0.05\right)$, but neither with segmental pain and temperature hypesthesia, nor with lost or reduced joint and touch sensation.

\section{Discussion}

This study shows that the recording of both spinal and scalp SEPs in patients with cervical spondylotic myelopathy can reveal two main types of cord dysfunction at the cervical level.

The most frequent SEP abnormality was the absence or reduction of the spinal N13 potential, which was evident in all but two patients, at least for one of the tested nerves. This abnormality was often associated with normal scalp SEPs, the loss of N13 with normal P14 and N20 potentials having been found in 28 of 76 upper limbs. A loss of N13 with normal P14 and $\mathrm{N} 20$ potentials is known to occur in lesions of the cervical grey matter leaving dorsal columns unaffected, such as cervical syrinxes ${ }^{11-14}$ and intramedullary tumours. ${ }^{15}$ Therefore, the isolated abnormality of the N13 potential in patients with cervical spondylotic myelopathy is thought to reflect an anatomical damage limited to the cervical grey matter. In a previous study, we proposed that this finding could reflect a decreased blood supply to cervical cord from anterior spinal artery. ${ }^{16}$ The 11 patients of this previous study have been selected from our cervical spondylotic myelopathy series because they presented normal sensations. The present study, which includes both these previous patients and other unselected cases, confirms that the finding of the isolated loss of the spinal N13 is not unusual in patients with cervical spondylotic myelopathy. A first reason for our high rate of $\mathrm{N} 13$ abnormalities, compared to the lower detection rates of upper limb SEPs in earlier studies, ${ }^{6-10}$ is that we did not use a neck to forehead montage for the recording of the N13 potential. The cervical response recorded with this montage is an amalgam of the cervical N13 and scalp P14 potentials ${ }^{1728}$ and is not significantly affected by selective lesions of the cervical grey matter. ${ }^{13-14}$ In fact, earlier SEP studies in patients with cervical spondylotic myelopathy failed to reveal any selective loss of the N13 potential in association with normal scalp potentials. In one of these reports, ${ }^{8}$ some upper limb abnormalities in SEPs were reported as reflecting a "proximal root/cord lesion" when showing abnormal cervical responses. The $\mathrm{N} 20$ potential was also abnormal, however, in all of these patients. Another reason for the rate of $\mathrm{N13}$ abnormalities in our patients pertains to the use of multiple nerve stimulation, including the radial nerve, which corresponds to the more frequently involved level.

Even though correlations between clinical signs and N13 abnormalities are not simple, abnormalities of the N13 potential are strongly related to the compression level as revealed by radiography and MRI investigations. Thus the higher rate of reduced N13 potentials in radial and median nerve SEPs than in ulnar nerve SEPs $(93.5 \%$ and $84.6 \%$ $v 65 \cdot 3 \%$ ) correlates well with the involvement of the C5 level as shown by MRI in all of our patients with this SEP abnormality. Moreover, 31 of 38 patients had no MRI evidence of cord compression below the sixth cervical vertebra. Conversely, in the two patients showing a normal N13 response after stimulation of all three nerves on both sides, the cord compression was located at the C2-C3 levels.

Electromyographic signs of denervation in upper limb muscles were present in many of our patients. Although we cannot exclude a radicular damage, it seems more likely that this finding was due to the involvement of the anterior horn cells; our patients in fact always presented a clear involvement of the spinal long tracts without radicular pain or paresthesiae.

Another frequent SEP feature in our patients was the abnormality of the P14 potential, which was found in $37.6 \%$ of radial, in $41 \%$ of median, and in $62.8 \%$ of ulnar scalp SEPs. It is generally agreed that the P14 scalp far-field potential is generated in the brainstem tracts of the ascending lemniscal pathways close to the cervicomedullary junction. ${ }^{17-20}$ Thus both increased P9-P14 interval or absent P14 with a normal P9, as found in all patients with abnormal P14 in this series, directly reflect time dispersion of

Table 3 Sensation, reflexes, and N13, P14 and N20 SEPs

\begin{tabular}{|c|c|c|c|c|c|c|}
\hline & \multicolumn{6}{|c|}{ Clinical features in corresponding upper limb } \\
\hline & \multicolumn{2}{|c|}{ Tendon reflexes } & \multicolumn{2}{|c|}{$\begin{array}{l}\text { Pain and temperature } \\
\text { sensation }\end{array}$} & \multicolumn{2}{|c|}{$\begin{array}{l}\text { foint and touch } \\
\text { sensation }\end{array}$} \\
\hline & Normal & Reduced & Normal & Reduced & Normal & Reduced \\
\hline $\begin{array}{l}\text { N 13: } \\
\text { Normal (5 upper limbs) } \\
\text { Abnormal ( } 71 \text { upper limbs) }\end{array}$ & $\begin{aligned} 5^{\star} \\
29^{\star}\end{aligned}$ & $\begin{aligned} 0^{\star} & - \\
42^{\star} & -\end{aligned}$ & $\begin{array}{r}5 \\
48\end{array}$ & $\begin{array}{r}0 \\
23\end{array}$ & $\begin{array}{r}1 \\
44\end{array}$ & $\begin{array}{r}4 \\
27\end{array}$ \\
\hline $\begin{array}{l}\text { P 14: } \\
\text { Normal (29 upper limbs) } \\
\text { Abnormal ( } 47 \text { upper limbs) } \\
\text { N 20: }\end{array}$ & $\begin{array}{l}14 \\
20\end{array}$ & $\begin{array}{l}15 \\
27\end{array}$ & $\begin{array}{l}24 \\
29\end{array}$ & $\begin{array}{r}5 \\
18\end{array}$ & $\begin{array}{l}29^{\star} \\
16^{\star}\end{array}$ & $\begin{aligned} 0^{\star} \\
31^{\star}\end{aligned}$ \\
\hline $\begin{array}{l}\text { Normal (35 upper limbs) } \\
\text { Abnormal (41 upper limbs) }\end{array}$ & $\begin{array}{l}17 \\
17\end{array}$ & $\begin{array}{l}18 \\
24\end{array}$ & $\begin{array}{l}27 \\
26\end{array}$ & $\begin{array}{r}8 \\
15\end{array}$ & $\begin{array}{l}33^{\star} \\
12^{\star}\end{array}$ & $29^{2 \star}$ \\
\hline
\end{tabular}


the ascending volley in the dorsal columns at the cervical level. In earlier studies, which used a cephalic reference montage, scalp SEP abnormalities in cervical spondylotic myelopathy were constantly represented by the abolition or latency delay of the parietal N20 response. The evaluation of abnormal dorsal column function provided by a prolonged N20 latency or N13-N20 interval is indirect, and includes the transit times in medial lemniscus and thalamocortical fibres; therefore any intracranial conduction slowing in the somatosensory pathways can cause an N20 abnormality. Our findings show that the evaluation of the scalp P14 far-field provides more reliable information on dorsal column dysfunction than that of the parietal N20 potential. Firstly, we found a greater percentage of abnormalities for P14 than for N20. In five patients, N20 was still recognisable and of normal latency, whereas the P14 was completely abolished or delayed (fig 2). This is the reason why the percentage of patients with subclinical dorsal column dysfunctions revealed by upper limb SEPs (normal joint and touch sensation but abnormal scalp SEPs) was greater in our series (32\%) than in those reported earlier (Yu and Jones ${ }^{8} 18 \%$; Veilleux and Daube ${ }^{9} 17 \%$ ). The abolition or the latency delay of the P14 potential with a normal N20 can be explained by the resynchronisation of the ascending volley in the intracranial somatosensory pathways. Secondly, by contrast with what has been seen for the $\mathrm{N} 20$ potential, ${ }^{8}$ we never found a normal P14 after stimulation of an upper limb presenting with lost or reduced joint and touch sensation.

Concerning the correlation between scalp SEP abnormalities and compression level, our data confirm that ulnar scalp SEPs are more often involved than median scalp SEPs. ${ }^{89}$ As the $\mathrm{C} 6$ and $\mathrm{C} 7$ myelomeres, receiving the sensory inputs from the median nerve, are located at the level of the fifth and sixth cervical vertebrae, it might be expected that patients with normal median nerve and abnormal ulnar nerve scalp SEPs would have a compression level below the sixth cervical vertebra. This assumption was not verified in our series, in which patients with isolated abnormality of the ulnar nerve P14 showed either a clear cut compression at the fifth and sixth cervical vertebra, or a multilevel compression involving myelomeres rostral to C8-T1. A greater sensitivity of the longer fibres to compression could account for the higher rate of abnormal ulnar nerve SEPs compared with median nerve SEPs in cervical spondylotic myelopathy. Due to the small difference in length between the fibres incoming from median and ulnar nerves, however, this explanation seems unlikely, even though it might hold for the high detection rate of tibial nerve SEPs in cervical spondylotic myelopathy..$^{89}$

1 Brain WR, Northfield D, Wilkinson M. The neurological manifestations of cervical spondylosis. Brain 1952;75: 187-225.
2 Adams C. Cervical spondylotic radiculopathy and myelopathy. In: Vinken PJ, Bruyn GW, eds. Handbook of clinical neurology, vol. 26: Injuries of the spine and spinal cord, part 2. Amsterdam: North Holland, 1976:97-112.

3 Ferguson RJ, Caplan LR. Cervical spondylotic myelopathy. Neurol Clin North Am 1985;3:373-82.

4 Al-Mefty O, Harkey LH, Middleton TH, Smith RR, Fox JL. Myelopathic cervical lesions and spondylotic lesions demonstrated by Magnetic Resonance Imaging. Neurosurg 1988;68:217-22.

5 Mehalic TF, Pezzuti RT, Applebaum BI. Magnetic Resonance Imaging and cervical spondylotic myelopathy. Neurosurgery 1990;26:217-27.

6 El-Negamy E, Sedgwick EM. Delayed cervical somatosensory potentials in cervical spondylosis. $f$ Neurol sensory potentials in cervical spond
Neurosurg Psychiatry 1979;42:238-41.

7 Ganes T. Somatosensory conduction times and peripheral, cervical and cortical evoked potentials in patients with cervical spondylosis. $f$ Neurol Neurosurg Psychiatry with cervical spo

$8 \mathrm{Yu} \mathrm{YL}$, Jones SJ. Somatosensory evoked potentials in cervical spondylosis. Correlation of median, ulnar and posterior tibial nerve responses with clinical and radiological findings. Brain 1985;108:273-300.

9 Veilleux M, Daube JR. The value of ulnar somatosensory evoked potentials (SEPs) in cervical myelopathy. Electroencephalogr Clin Neurophysiol 1987;68:415-23.

10 Perlik SJ, Fisher MA. Somatosensory evoked response evaluation of cervical spondylitic myelopathy. Muscle Nerve 1987;10:481-9.

11. Emerson RG, Pedley TA. Effect of cervical spinal cord lesions on early components of the median nerve somatosensory evoked potentials. Neurology 1986;36: 20-6.

12 Urasaki E, Wada S, Kadoya C, Matsuzaki H, Yokota A Matsuoka S. Absence of spinal N13-P13 and norma scalp far-field P14 in a patient with syringomyelia. Electroencephalogr Clin Neuitophysiol 1988;71:400-4.

13 Restuccia D, Mauguière F. The contribution of median nerve SEPs in the functional assessment of the cervical spinal cord syringomyelia. Brain 1991;114:361-79.

14 Mauguière $F$, Restuccia $D$. Inadequacy of the forehead reference montage for detecting abnormalities of the spinal N13 SEP in cervical cord lesions. Electroencephalogr Clin Neurophysiol 1991;79:448-56.

15 Ibañez V, Fischer G, Mauguière F. Dorsal horn and dorsal column dysfunction in intramedullary cervical cord tumours. A somatosensory evoked potential study. Brain 1992;115:1209-34.

16 Restuccia D, Di Lazzaro V, Valeriani $M$, Tonali $P$ Mauguière F. Segmental dysfunction of the cervical cord revealed by abnormalities of the spinal N13 potencord revealed by abnormalities of the spinal N13 poten-
tial in cervical spondylotic myelopathy. Neurology tial in cervical

17 Mauguière F, Ibañez V. The dissociation of early SEP components in lesions of the cervicomedullary junction a cue for routine interpretation of abnormal cervical responses to median nerve stimulation. Electroencephalogr Clin Neurophysiol 1985;62:406-20.

18 Yamada T, Ishida T, Kudo Y, Rodnitzky R, Kimura J. Clinical correlates of abnormal P14 in median SEPs. Neurology 1986;36:765-71.

19 Garcia-Larrea L, Mauguière F. Latency and amplitude abnormalities of the scalp far-field P14 to median nerve stimulation in multiple sclerosis. A SEP study of 122 patients recorded with a noncephalic reference montage. patients recorded with a noncephalic reference mon

20 Turano G, Jones SJ, Miller DH, de Bolay GH, Kakigi R McDonald WI. Correlation of SEP abnormalities with brain and cervical cord MRI in multiple sclerosis. Brain brain and cervical

21 Daube JR. Nerve conduction studies. In: Aminoff MJ, ed. Electrodiagnosis in clinical neurology. New York: Churchil Livingstone, 1986:265-306

22 Desmedt JE, Nguyen TH. Bit-mapped colour imaging of the potential fields of propagated and segmental subcortical components of somatosensory evoked potentials in man. Electroencephalogr Clin Neurophysiol 1984;58. 481-97.

23 Desmedt JE, Cheron G. Central somatosensory conduction in man: neural generators and interpeak latencies of the far-field components recorded from neck and right or left scalp and earlobes. Electroencephalogr Clin or left scalp and earlobes.

24 Desmedt JE, Cheron G. Prevertebral (oesophageal) recording to subcortical somatosensory evoked potenrecording to subcortical somatosensory evoked potentials in man: the spinal P13 component and the dual nature of the spinal generators.
Neurophysiol $1981 ; 52: 257-75$.

25 Anziska BJ, Cracco RQ. Short latency SEPs to median nerve stimulation: comparison of recording methods and origin of components. Electroencephalogr Clin Neurophysiol 1981;52:531-9.

26 Lüeders H, Lesser R, Hahn J, Little J, Klem G. Subcortical somatosensory evoked potentials to median nerve stimulation. Brain 1983;106:341-72.

27 Yamada T, Kimura J, Nitz DM. Short latency somatosensory evoked potentials following median nerve stimulation in man. Electroencephalogr Clin Neurophysiol 1980 48:367-76.

28 Mauguière F. Les poténtiels évoqués somesthesiques cervicaux chez le sujet normal: analyse des aspects obtenus selon le siège de l'électrode de réfèrence. Rev Electroencephogr Neurophysiol Clin 1983;13:259-72. 